\title{
Cosmopolitismo e multiculturalismo: avaliações a partir de uma comunidade quilombola*
}

\section{Cosmopolitanism and Multiculturalism: considerations from the Quilombola Community}

\author{
Gisele Cittadino* \\ Katarina Pitasse Fragoso ${ }^{* * *}$
}

\section{Resumo}

O texto apresenta um estudo crítico sobre duas teorias da justiça: a cosmopolita, desenvolvida por Thomas Pogge, e a multicultural, por Will Kymlicka. Do primeiro, investigam-se as vantagens de se ter uma preocupação moral com os habitantes do mundo, destacando as desvantagens de se ignorar as singularidades culturais. Do segundo, ressalta-se a prioritária legitimidade das demandas culturais. Apresenta-se, assim, a importância dos direitos diferenciados em prol das minorias nacionais e dos grupos étnicoculturais e, ao mesmo tempo, evidencia-se o limite dessas categorias culturais que não costumam dar conta, por exemplo, do grupo negro que reivindica reconhecimento cultural. Por fim, será desenvolvido um exercício prático com as referidas teorias, propondo a aplicação dos conceitos apresentados diante do caso concreto de uma comunidade de quilombolas de Linharinho, localizada na parte rural e pobre do município de Conceição da Barra, no Espírito Santo, que possui demandas relacionadas a direitos políticos, sociais e culturais.

Palavras-chave: Justiça social. Cosmopolitismo. Multiculturalismo. Comunidade de quilombolas de Linharinho.

* O artigo está vinculado à linha de pesquisa Direitos Humanos, Democracia e Ordem Internacional do PPGD/PUC-Rio e ao projeto de pesquisa Multiculturalismo, Autonomia e Constituição, financiado pelo CNPq

* Doutora em Ciência Política pelo Instituto Universitário de Pesquisas do Rio de Janeiro. Professora do Programa de Pós-Graduação em Direito da PUC-Rio. Rio de Janeiro - RJ - Brasil. E-mail: gisele@puc-rio.br

*** Doutoranda em Filosofia da Université Catholique de Louvain (Bolsista CAPES). Louvain-laNeuve, Bélgica. E-mail: katarina.fragoso@gmail.com 


\section{Abstract}

This article presents a critical study of two theories of justice: cosmopolitanism and multiculturalism as developed by Thomas Pogge and Will Kymlicka respectively. We first investigate the advantages of having moral obligations towards the inhabitants of the world, and we also highlight the disadvantages of leaving cultural particularities out. Second, we focus on the priority of the legitimacy of cultural demands. Bearing this in mind we discuss the importance of differential rights in favour of national minorities and of ethnic-cultural groups. But, at the same time, we expose the limitations of those cultural categories given that they usually neglect, for instance, the claims for cultural recognition made by black peoples. Lastly, in order to apply their concepts, we carry out an exercise with the two theories in light of one concrete case: the Quilombolas community in Linharinho. Located in the rural and poor municipality of Conceição da Barra, in Espirito Santo, this community has demands related to political, social, and cultural rights.

Keywords: Social justice. Cosmopolitanism. Multiculturalism; the Quilombolas community in Linharinho.

\section{Introdução}

Um cenário de pessoas desamparadas e segregadas, que vivem em ambientes cruéis e são frequentemente desrespeitadas, pode ser encontrado em qualquer lugar do mundo. Algumas dessas imagens terríveis descortinam aquilo que costumamos designar como "injustiça". O que tais representações provocam nos indivíduos que as observam? Há preocupação com o sofrimento de pessoas que enfrentam dificuldades materiais? A representação da dor do outro gera obrigações morais? Qual a legitimidade das políticas em prol dos grupos socialmente discriminados por conta de elementos étnico-culturais? São essas as questões que costumam nortear os estudos sobre justiça.

Há duas formas de avaliar moralmente os fatos que acontecem no mundo, de acordo com Thomas Pogge: interativamente, ou seja, pelas ações e efeitos realizados pelos agentes individuais e coletivos; 
e institucionalmente, isto é, através dos mecanismos de organização da sociedade, como as leis, as convenções e as instituições sociais. Segundo Pogge, John Rawls, na obra Uma Teoria da Justiça, defendeu que "as instituições sociais são uma esfera separada da valoração moral e constituiu uma terminologia associando essa esfera aos conceitos de justiça e justiça social" (POGGE, 2008b, p. 101-102). Tais construções terminológicas ganharam adesão, tanto que, contemporaneamente, de acordo com Pogge, os estudos de justiça se concentram mais nas análises das normas sociais, como leis, práticas, convenções e instituições sociais, do que na valoração do caráter e comportamento dos agentes individuais e coletivos.

Will Kymlicka, por sua vez, afirma, em conformidade com Rawls, que as ideias de justiça, liberdade, igualdade e comunidade normalmente são invocadas para a avaliação de "instituições e procedimentos políticos", determinando que todos os afetados por uma estrutura ou instituição sejam sujeitos de justiça (KYMLICKA, 2006, p. 1). Desse modo, tanto Pogge quanto Kymlicka endossam as delimitações de Rawls, sustentando que a justiça será garantida por meio de arranjos institucionais que permitem a interação de todos como pares na vida em sociedade.

Além do apelo institucional, o modelo de justiça também pode abarcar as dimensões econômica, cultural e política, como apontou Nancy Fraser, ao considerar que a luta por justiça social no mundo globalizado deve ocorrer em três frentes simultâneas: contra a má distribuição, a desigualdade de status e a falsa representação (FRASER, 2009, p. 17). Neste texto, endossamos a hipótese de que essas três dimensões podem ser núcleos de uma proposta de justiça, visto que há casos concretos complexos que demandam um intercruzamento e recíproca influência entre eles.

Esta é, por exemplo, a questão enfrentada pela comunidade de quilombolas de Linharinho: um agrupamento social composto por plantadores rurais, descendentes de escravos, com particularidades étnico-raciais e dificuldades econômicas. Esses quilombolas lutam para 
permanecer no local onde vivem, assegurando suas práticas culturais, e almejam recursos materiais para sobreviver, ou seja, carecem tanto de direitos sociopolíticos, quanto de culturais.

Três momentos, portanto, estruturam este artigo. O primeiro está direcionado ao problema de como defender uma preocupação moral diante da construção teórica da justiça global. Aapresentação do problema será conduzida a partir da exposição dos argumentos de Thomas Pogge desenvolvidos, principalmente, na obra World Poverty and Human Rights (2008). O segundo pretende aventar uma hipótese que complemente a moldura global de combate à desigualdade material com as discussões em torno da defesa das experiências culturais. Dessa maneira, valese do aporte multicultural desenvolvido por Will Kymlicka, exposto nas obras Multicultural odysseys, Navigating the New International Politics Of Diversity (2007) e Multicultural Citizenship: A liberal theory of minority rights (1995). Em um terceiro momento, após o debate conceitual, será analisado o caso da comunidade de quilombolas de Linharinho, localizada na parte rural e pobre do município de Conceição da Barra, no Espírito Santo. Os integrantes do grupo são plantadores rurais com particularidades étnicas, que emergem, por exemplo, na dança de tambores tradicional, no sincretismo religioso, na memória comum de discriminação étnico-racial e, por fim, na ideia de que a terra é um lugar de pertencimento. Para manter essas singularidades, o grupo enfrenta lutas diárias, agravadas pelas dificuldades advindas da falta de recursos materiais e da falsa representação política.

\section{Thomas Pogge e a justiça global}

Thomas Pogge, em World Poverty and Human Rights, preocupase especialmente com a justiça global ou cosmopolita, em face da extensão e severidade da fome e da pobreza extrema mundial. Busca, dessa maneira, um critério de justiça que avalie se as instituições de um sistema social tratam os indivíduos de modo moralmente apropriado. Esse critério seria encontrado nos direitos humanos. 
A linguagem dos direitos humanos, segundo Pogge, incide diretamente nos arranjos sociais e indiretamente nas condutas dos agentes morais, tendo como fim resguardar os direitos básicos de todos. Os conteúdos dos direitos humanos estariam comprometidos com o reconhecimento de que há necessidades básicas que circunscrevem os interesses identificados por cada indivíduo. Por essa razão, a pobreza extrema seria uma violação dos direitos humanos.

Pogge foca no seguinte problema: "como os direitos humanos poderiam ser concebidos? O que representa um direito humano, especialmente no que diz respeito às suas correlativas responsabilidades?" (POGGE, 2008a, p. 59). Tais questões não podem ser respondidas se não procurarmos compreender os fundamentos dos direitos humanos. Segundo o autor, os direitos humanos têm compromisso com certas reivindicações básicas que os indivíduos, de contextos e culturas diferentes, possuem. Ao desenhar uma concepção moral desses direitos e reconstruir o significado da seguinte expressão, "eu pergunto o que nós dizemos, ou queremos dizer, quando afirmamos que alguém tem um direito humano", POGGE, 2008a, p. 64), Pogge deseja encontrar o que seria moralmente aceitável quando um direito humano é observado.

O suporte moral do argumento de Pogge está expresso no artigo 28 da Declaração Universal dos Direitos Humanos (DUDH), conforme se lê: "toda pessoa tem o direito a uma ordem social e internacional em que os direitos e as liberdades estabelecidos na presente Declaração possam ser plenamente realizados". A DUDH, portanto, explicitou uma demanda moral já existente na sociedade e, ainda, uma preocupação de que os direitos humanos morais não se concentram, no primeiro momento, nos aportes jurídicos, e sim no comprometimento empírico, ou seja, na garantia real de acesso ao seu conteúdo. Cumpre, agora, compreender as justificativas desse projeto político de justiça global.

Pogge anuncia três causas para a permanência da pobreza extrema mundial, a saber: a existência de uma ordem econômica global que beneficia os países ricos e agrava as desigualdades sociais, a 
exclusão não compensada do uso de uma base comum de recursos naturais e, por último, os efeitos de uma história compartilhada e violenta.

Em conformidade com a primeira causa, os desfavorecidos no mundo estão inseridos em contextos que foram determinados pelas redes de trocas mercadológicas, traduzidas pelos acordos internacionais, blocos econômicos e contratos multilaterais. Tal conjuntura favorece os países ricos e, consequentemente, gera efeitos devastadores para os países pobres. Os cidadãos abastados e os países ricos, seja propositalmente ou não, sustentam uma ordem mundial que produz a pobreza extrema e alarga a desigualdade social ${ }^{1}$. Dessa maneira, os famintos não acessam os conteúdos dos diretos humanos devido às atuações dos arranjos institucionais internacionais que moldam e delimitam suas vidas à margem do sistema produtivo. Contudo, tal constatação não significa que todos sejam responsabilizados pelos efeitos injustos, e tampouco que a estrutura de interdependência global deva ser desfeita. Por ora, importa o envolvimento e a responsabilidade moral, associados ao dever negativo de não perpetuar a desigualdade social e a miséria de muitos.

A segunda causa, por sua vez, diz respeito à distribuição desigual da exploração dos recursos naturais, como petróleo, minerais e outros bens, que favorecem as elites econômicas e políticas. Segundo Pogge, os indivíduos economicamente privilegiados se apropriam e se beneficiam dos recursos naturais, de tal forma que os demais não são compensados, nem o meio ambiente respeitado. Dessa maneira, os Estados e cidadãos dos países ricos estão violando um dever negativo - às vezes corroborados pelas elites dos países pobres - ao excluírem imperativamente os desfavorecidos de uma parcela considerável dos recursos naturais.

A pobreza extrema diz respeito à situação onde o indivíduo não tem acesso seguro aos direitos básicos, como alimento, vestuário, educação e saúde, vivendo com (ou menos) de 2 dólares diários. Já a desigualdade é a conjuntura em que há assimetria entre os ricos e pobres, de tal forma que os primeiros são beneficiados e os últimos prejudicados. (POGGE, 2006, p. 34-41) 
A última causa da pobreza mundial está atrelada aos efeitos devastadores de uma história comum e violenta. Pogge aqui alerta para o fato de que as posições sociais dos mais ricos e dos pobres surgiram de um mesmo processo histórico, marcado pela acentuada conquista, colonização e escravidão. Esse argumento pode abarcar um mal entendido, porque não se trata de uma posição em prol de reparações. Por isso, Pogge sustenta que não se deve imputar uma responsabilidade restitutiva em função de erros dos antepassados, mas torna-se necessário reconhecer que as discrepâncias foram geradas por meios sociais injustos. Assim, não é moralmente defensável a desigualdade social existente, visto que está configurada por contextos históricos, nos quais os princípios morais e as crenças legais foram amplamente violados.

Há, então, um cenário mundial de sistemas interconectados que justificam pensar a justiça no âmbito internacional. Esse contexto ocasiona injustiças e tem como efeito a pobreza extrema e a desigualdade social. Nas palavras de Pogge:

Estima-se que 831 milhões de seres humanos são cronicamente subnutridos, 1 bilhão e 197 milhões não têm acesso à água potável e 2 bilhões e 747 milhões não têm acesso ao saneamento básico (Programa das Nações Unidas para o Desenvolvimento, UNDP 2004:129-30) [...]. Aproximadamente um terço de todas as mortes humanas (cerca de 18 milhões anualmente) é devido a causas relacionadas a pobreza, as quais seriam facilmente evitáveis através de melhor nutrição, água potável, alimentos hidratáveis de baixo custo, vacinas, antibióticos, e outros medicamentos. (POGGE, 2006, p. 35)

Os arranjos institucionais e as redes globais que circunscrevem as trocas econômicas nacionais e internacionais determinam, direta ou indiretamente, as causas que, em grande parte, agravam a incidência e a profundidade da pobreza extrema no mundo. De acordo com Pogge, essa situação é alarmante, tornando-se forçoso, primeiro, romper a separação entre as fronteiras, pois há o compartilhamento de 
responsabilidades, e, em seguida, estender, de maneira imparcial, a preocupação moral para todos os indivíduos do mundo.

Contudo, mesmo considerando tais argumentos, ainda existem objeções razoáveis que poderiam ser oferecidas para rejeitar essa concepção de justiça social aplicada aos arranjos institucionais transnacionais. De acordo com Pogge, duas construções são possíveis, ambas defendidas por John Rawls²: a inviabilidade de um Estado mundial e a dificuldade de estabelecer a justiça social, distintamente liberal, nas variadas culturas existentes ${ }^{3}$.

Rawls não explicitou em seus escritos sobre justiça internacional uma concepção cosmopolita ou global direcionada para todas as pessoas. Primeiro, o autor sustenta a manutenção das estruturas políticas dos Estados-nação, destacando a inviabilidade de um Estado mundial. Em seguida, pretende aplicar seus princípios de justiça internacional apenas para algumas sociedades, notadamente, as compostas por povos liberais e decentes. Segundo Pogge, a primeira objeção construída por Rawls - a da inviabilidade de um Estado mundial - não apresenta bons fundamentos e escapa à sua perspectiva de cosmopolitismo. Isso ocorre porque se o Estado mundial estivesse associado à concentração da soberania, possivelmente redundando em grandes perigos, como o despotismo e a guerra civil, a concepção cosmopolita de justiça social, por seu turno, poderia oferecer outro desenho institucional que melhor garantisse os interesses fundamentais dos seres humanos, identificado com a descentralização da autoridade governamental e da soberania nacional. Nesse último modelo, a autoridade política poderia dispersar-se em diferentes níveis interdependentes, algo parecido com o federalismo global da União Europeia ou com a liga das nações descrita por Kant, na obra A paz perpetúa (POGGE, 2007a, p. 317).

2 De acordo com Pogge (2007a), Rawls, na obra O Direitos dos Povos, rejeita essa interpretação cosmopolita de justiça social, pois pretendia aplicar os seus princípios de justiça política apenas para algumas sociedades nacionais.

3 Rawls não chega a reconhecer a existência de responsabilidades morais entre os países ricos e os pobres. Esse argumento foi desenvolvido por Francisco Cortés Rodas e Thomas Pogge. Para maiores informações, consultar RODAS, 2010, p. 101 e POGGE, 2004, p. 38. 
Com relação à segunda objeção ao argumento de Rawls sobre a existência de diversidade cultural que vai além dos povos liberais e decentes, Pogge reconhece esta preocupação e defende que a sua concepção de justiça social deve ser compartilhada por diferentes culturas, sem que elas sejam desrespeitadas. Sustenta, assim, que uma concepção de justiça social não precisa ser excessivamente ocidental ou liberal para que possa ser compartilhada por culturas diferentes; todavia, não há como ser realizada se não for satisfatória para todos.

Há, aqui, o reconhecimento de que a pobreza de um estranho, desconhecido ou estrangeiro será objeto de preocupação moral. Daí a preocupação do autor em garantir para todos o acesso seguro ao conteúdo dos direitos humanos (POGGE, 2008a). No entanto, ao constituir um critério de compartilhamento de valores e bens universais de justiça, Pogge permite o aparecimento de argumentos que podem ser interpretados como imposições de um grupo social sobre outro ou como falta de sensibilidade e diálogo com as singularidades locais. Não é por outra razão que precisamos trazer ao debate o reconhecimento da diversidade cultural e as formas de lidar com as minorias, a partir das construções teóricas de Will Kymlicka.

\section{Will Kymlicka e o multiculturalismo liberal}

Algumas minorias nacionais e étnicas podem estar insatisfeitas com as políticas individualistas dos direitos humanos. Segundo Kymlicka, há três exemplos centrais ${ }^{4}$ que poderiam demonstrar este ponto de vista e, consequentemente, os limites desse critério normativo: as disposições sobre políticas de migração/povoamento, as decisões sobre as fronteiras e os poderes das unidades políticas internas e, por último, as questões sobre o estabelecimento de línguas oficiais.

De acordo com Kymlicka (2011), outras práticas poderiam igualmente demonstrar a cultura dominante - e a insuficiência dos direitos humanos em garantir a justiça cultural - como os feriados públicos, o currículo escolar, os símbolos nacionais e outros códigos. 
As políticas de migração/povoamento, normalmente, são utilizadas contra as minorias nacionais, porque cerceiam o acesso aos recursos naturais e restringem a atuação política desses grupos. Para Kymlicka, tais políticas de povoamento expõem uma fonte de injustiça e de violência que os direitos humanos, mesmo sendo abrangentes, não são capazes de fornecer suporte normativo para solucioná-la.

Já as fronteiras e os poderes das unidades políticas internas emergem como questões fundamentais de justiça. Contudo, muitas das demarcações territoriais inventadas pelos países dominantes desmantelam o poder e a representação política das minorias nacionais. De acordo com Kymlicka, os direitos humanos tampouco ajudam a impedir esta injustiça.

Por fim, as políticas relativas às línguas oficiais, das escolas, dos tribunais e das instituições nacionais, subsumem as práticas culturais das minorias nacionais, ao obrigá-las a se enquadrar na lógica linguística dos grupos majoritários. Da mesma forma que nos casos anteriores, os direitos humanos não são capazes de relativizar essa política majoritária.

Para Kymlicka, portanto, torna-se necessário encontrar nos direitos humanos a defesa dos direitos das minorias, ao garantir a sua língua, a representação política, a diversidade cultural e o acesso à terra. A fissura está não só no reconhecimento das diferenças, mas também na busca de como corrigir as desigualdades e como enquadrar tais demandas culturais. Ao expor os limites dos direitos humanos, Kymlicka não pretende negar a importância desse critério de justiça, mas assegurar que ele seja complementado ${ }^{5}$ pelos direitos básicos das minorias nacionais e étnicas (KYMLICKA, 2011:37).

Em um ambiente social e culturalmente heterogêneo, Kymlicka, no livro Multicultural Citizenship: A liberal theory of minority rights, distingue as "minorias nacionais", entendidas como sociedades distintas

Essa posição de Kymlicka perdura nos seus primeiros escritos; a partir de 2007, os direitos humanos precisariam ser complementados pelos direitos culturais. 
e potencialmente autogovernadas que foram incorporadas a um Estado mais amplo por meio de conquistas, colonização ou federação, dos "grupos étnico-culturais", que são representados pelos imigrantes que deixam a sua comunidade originária para incorporarem-se a outra. O primeiro grupo, denominado de "minoria nacional", existente anteriormente ao processo de formação do Estado-nação, foi a ele involuntariamente incorporado; o segundo, os "grupos étnico-culturais", aderiram voluntariamente, renunciando a alguns direitos que fazem parte da sua origem nacional. De acordo com Kymlicka, estas são as duas fontes mais comuns de diversidade cultural nos Estados modernos e, por isso, possibilitam a feitura de modelos de justiça multicultural (KYMLICKA, 1995, p. 10-18, 2001, p. 57).

As minorias nacionais e os grupos étnico-culturais aspiram ao reconhecimento cultural. De um lado, as minorias nacionais desejam manter suas peculiaridades linguísticas e simbólicas, por meio dos direitos de autogoverno; de outro, os grupos étnico-culturais almejam fazer parte da sociedade, como membros de pleno direito, desde que possam manter as suas identidades, cujas demandas são representadas pelos direitos poli-étnicos. Torna-se evidente, assim, a luta por leis mais permeáveis que sejam compatíveis com as justas reivindicações dos grupos sociais que se encontram em desvantagem.

Apesar dessa distinção entre os grupos, há complexidades que envolvem as políticas multiculturais e que transcendem qualquer tentativa de simplificação ou categorização. Há outros grupos que não se ajustam claramente às categorias de minorias nacionais ou étnicas. Kymlicka admite a limitação dessas divisões ao expor, por exemplo, o caso dos negros, dos refugiados, dos ciganos e dos russos do Báltico, que não se enquadrariam nem como minorias nacionais, nem como minorias étnicas ${ }^{6}$.

Dada a pluralidade de grupos e, consequentemente, das diferentes demandas, toda política que busca implementar o multiculturalismo

6 Para mais informações sobre essa desvantagem, BARRY, 2001; VITA, 2002. 
liberal a partir de uma única perspectiva ou, ainda, por meio de direitos genéricos, será insuficiente. Esse é o entendimento de Kymlicka, evidenciado na seguinte afirmação: "a lógica do multiculturalismo liberal não pode ser capturada através das sentenças 'toda minoria tem direito a $x$ ' ou 'toda pessoa que pertence a uma minoria tem direito a x"” (KYMLICKA, 2007a, p. 7). Portanto, não é possível pensar em políticas voltadas para as minorias por meio de aportes institucionais muito amplos que exijam generalizações, pois isso denota ausência de sensibilidade local.

Para dar conta dessa sensibilidade e comunicação com os laços de pertencimento, as alteridades e as perspectivas locais, Kymlicka, em seguida, apresenta três mecanismos de direitos diferenciados ${ }^{7}$ que serviriam para harmonizar as peculiaridades culturais existentes, sem, contudo, suprimi-las. São eles: os direitos de autogoverno ${ }^{8}$, os direitos poli-étnicos e os direitos especiais de representação.

Os direitos de autogoverno estão garantidos, com ressalvas, pela Carta das Nações Unidas e conferem poderes às unidades políticas controladas pelos membros dos grupos minoritários. No documento internacional, todos os povos têm o direito de autogoverno; para Kymlicka, no entanto, a declaração é muito genérica, pois não define quem são os povos detentores de tal direito. Uma forma de desenvolvimento desses direitos, segundo ele, seria através da descentralização do governo, como, por exemplo, pelo federalismo. Nesse cenário, o poder é repartido entre o governo central e as subunidades regionais. No entanto, o federalismo só pode servir como mecanismo de reconhecimento do autogoverno se, e somente se, a minoria nacional constituir uma maioria em uma das subunidades federais, como ocorre em Quebec, no Canadá.

Kymlicka prefere o termo "direitos diferenciados" do que "direitos coletivos". Para o filósofo, o termo "direitos coletivos" é muito amplo, não distinguindo as formas de direitos que podem gerar a opressão individual (KYMLICKA, 1995, p. 45).

8 Neste artigo, optou-se por traduzir self-government rights por "direito de autogoverno" e, assim, ser mais fiel ao uso do autor, mesmo sendo uma palavra pouco usada na literatura brasileira. 
Os direitos poliétnicos objetivam assegurar a expressão das particularidades culturais dos grupos e, ao mesmo tempo, possibilitar a sua integração na sociedade. Assim, buscam proteger as tradições, religiões e culturas, por meio de ações institucionais e projetos políticos e evitar a submissão do grupo à sociedade dominante.

Por fim, os direitos especiais de representação asseguram que um grupo minoritário não será desconsiderado diante das questões que afetam a sociedade. Desse modo, possuem a função de garantir o espaço deliberativo para os grupos politicamente alijados. Kymlicka, nesse tema, sugere a admissão das minorias em partidos políticos, a representação proporcional e as ações afirmativas.

\section{O desafio do caso concreto do Quilombo de Linharinho}

Uma vez apresentadas as construções conceituais de Pogge e Kymlicka, a proposta é utilizá-las a partir da seguinte questão: como a justiça institucional deve ser efetivada? Ao tomar como caso concreto um grupo da comunidade de quilombolas ${ }^{9}$, em que se verifica a falta de reconhecimento cultural e a escassez de recursos econômicos, pretende-se observar de que maneira a injustiça pode ser dissolvida.

Os membros do grupo, a família Santos, são plantadores rurais com particularidades étnico-raciais que emergem, por exemplo, na dança de tambores tradicional chamada "Jongo", no sincretismo religioso, percebido na contemplação de Santa Bárbara, nas oferendas do Candomblé, nas rezas da igreja Católica, na memória comum de discriminação étnico-racial e, por fim, na ideia de que a terra é um lugar de pertencimento. Além dessas tradições, permanece a prática da

Os dados da pesquisa relacionados ao grupo quilombola foram baseados na tese de doutorado e no artigo do antropólogo Sandro Dias. Paralelamente ao uso dessas fontes, a pesquisadora Katarina Pitasse visitou a comunidade de Linharinho, no dia 26 de janeiro de 2014, e conversou com o grupo, sobretudo com a Dona Miúda, uma das lideranças locais. Optou-se em desenvolver uma conversa com a finalidade de manter um ambiente menos intimidador, portanto não foram feitos registros, como entrevista e questionário. Para maiores informações sobre o grupo, SILVA, 2012; SILVA, 2013. 
fabricação de farinha de mandioca, que dá origem à tapioca e aos beijus. Todas essas atividades são familiares, e os mais jovens e mais velhos participam conjuntamente. Esse aspecto familiar do grupo possibilita a ajuda mútua, a união e a cumplicidade entre os indivíduos que vivem em Linharinho e se identificam como quilombolas.

A invisibilidade e a tranquilidade dos moradores do quilombo de Linharinho duraram pouco, pois o comércio de celulose se intensificou, comandando a lógica da política local e descortinando a comunidade que lá morava. As empresas exploradoras de celulose tinham como interesse angariar mais terras para o cultivo do eucalipto e, para tanto, utilizaram a violência, o desrespeito aos direitos humanos, além de ferirem a identidade cultural dos negros que ali viviam. As dificuldades e os embates diários enfrentados pelo grupo foram potencializados por duas causas: a diminuição das terras, que hoje pertencem, majoritariamente, aos exploradores de celulose, e a aspereza e a infertilidade do solo agravadas pelo monocultivo do eucalipto.

No que concerne à primeira causa, cabe destacar, segundo a história oral e a memória coletiva ${ }^{10}$, que a comunidade existe há mais de 200 anos. Inicialmente, seus integrantes trabalhavam nas fazendas do entorno e, ao mesmo tempo, construíram suas vidas nas terras que sobravam, sem nunca terem regulamentado o território. Com o passar dos anos, as fazendas desapareceram e cederam lugar às empresas exploradoras, como a Aracruz Celulose (hoje, Fibria). Desde a década de 1960, muitos dos conflitos ocorreram nos territórios responsáveis pela sobrevivência do grupo e pela identificação cultural e, por isso, os quilombolas lutam pela permanência e manutenção de suas tradições. Contudo, o poder oficial não repara e não se interessa pelas singularidades ali construídas, empregando artimanhas jurídicas - como a falta do título de propriedade - para beneficiar as grandes empresas e, em contrapartida, fragilizar o grupo. Essas ações políticas injustas

\footnotetext{
10 Para as discussões sobre os conceitos de oralidade, história oral e memória: FERREIRA, 1996;
} ALBERTI, 2004. 
culminaram em perdas de muitas terras, diminuindo a capacidade de plantação dos quilombolas de Linharinho e aumentando o cultivo do eucalipto.

Já quanto à segunda causa, um desdobramento da primeira, a principal atividade das famílias do quilombo de Linharinho se concentra na plantação de hortas para alimentação própria e venda dos excedentes, como mandioca, cana-de-açúcar, café, abóbora, entre outros legumes e frutas. Todavia, desde o final da década de 1990, com pouca terra para plantar e a intensificação da seca, o grupo passou a se dedicar à produção de carvão feito por meio de resíduos do eucalipto, conhecido como "facho". Os quilombolas, no entanto, não guardam relações culturais com a atividade realizada nos fornos de carvão, visto que ela gera neles um sentimento de vergonha. O grupo reivindica formas dignas de viver na roça, obtidas, segundo eles, através das plantações, e não na produção de carvão. Nesse cenário, os quilombolas ressaltam como principal entrave para o retorno de sua tranquilidade, a apropriação indevida de seus territórios.

O cenário descrito pelos quilombolas é verificado por qualquer observador que visite a comunidade. Indo de São Mateus à Conceição da Barra, avista-se da estrada o verde homogêneo do monocultivo do eucalipto; mas também é possível enxergar a terra muito seca e a pobreza social. Ao chegar à rodoviária de Conceição da Barra, percorre-se mais 20 minutos de estrada de chão e, enfim, encontra-se a comunidade quilombola de Linharinho. Lugar de muitas histórias, lutas e união, simbolicamente representadas pela disposição das casas, pois não há cercas e demarcações de território, e, também, pela memória comum e pelo sentimento de coletividade.

Alguns fatores impostos, como a plantação do eucalipto e os manejos das políticas locais, causaram temor ao grupo. A atividade de plantar ficou prejudicada. Desse modo, enquanto o eucalipto cresce e os lucros das empresas aumentam, cada vez mais o solo seca e a comunidade se retrai. Palavras de um dos quilombolas: "acabou a água, acabou o peixe, acabou a caça, acabou tudo; a empresa tirou tudo e 
em troca tava dando cadeia, processo, tem vários processados" (SILVA, 2013a, p. 22).

Diante dessa situação alarmante, o Estado desaparece, negligenciando o suporte institucional às famílias dos quilombolas. Muitos foram expulsos ou tiveram seu direito de ficar restrito à fiscalização da empresa exploradora de celulose que determina as regras que submetem a comunidade. Assim, os sujeitos que permaneceram, resistem e enfrentam lutas diárias para continuarem nas suas terras e manterem vivas suas tradições.

No documentário "Raça", lançado em 2012, dirigido por Joel Zito Araújo e Megan Mylan, mostra-se, em determinado momento, uma manifestação política organizada pelos quilombolas do Sapê do Norte, incluindo a família Santos, no ano de 2009. Nela, os quilombolas fecharam a BR 101 com pneus e tocos de eucalipto em chamas, impedindo o tráfico. Essa movimentação tinha por objetivo revelar sua própria existência e lançar um grito político por direitos socioculturais.

Com a Constituição de 1988, os quilombos foram inseridos no debate das políticas nacionais através da previsão do artigo 68 dos Atos das Disposições Constitucionais Transitórias (ADCT) $)^{11}$, que buscou reconhecer a propriedade definitiva para estas comunidades. Em 2003, o decreto federal $n^{\circ} 4887$ foi aprovado e passou a regulamentar "o procedimento para identificação, reconhecimento, delimitação, demarcação e titulação das terras ocupadas pelas comunidades dos quilombolas de que trata o art. 68 do Ato das Disposições Constitucionais Transitórias" (BRASIL, 2003). Por meio desses dispositivos normativos, novas expectativas são anunciadas, como a possibilidade de acesso ao reconhecimento cultural e a garantia da formalização do território dos quilombolas.

Ainda que exista um decreto específico para resguardar o território, a cultura e as tradições dos quilombolas, na prática o direito

\footnotetext{
11 Art. 68 - Aos remanescentes das comunidades dos quilombos que estejam ocupando suas terras é reconhecida a propriedade definitiva, devendo o Estado emitir-Ihes os títulos respectivos.
} 
oficial não dá conta das demandas do grupo. A instabilidade ocasionada pela possibilidade de serem retirados a qualquer momento de suas terras, seja por interesses políticos, seja por questões econômicas, esmaga, sob todos os aspectos, as famílias quilombolas. Muitas vezes, como já destacado, elas precisam deixar de lado uma prática cultural, como o plantio das hortas, e são impelidas a se dedicarem à produção de carvão. Segundo as pesquisas apresentadas por Sandro Silva, 83\% dos quilombolas se declaram pretos, $54 \%$ dos quilombolas recebem menos de um salário mínimo, $70 \%$ possuem como atividade principal a agricultura e 73\% não terminaram o ensino fundamental (SILVA, 2013a, p. 6). Para além das questões culturais e políticas, percebe-se que o grupo de quilombolas precisa de condições socioeconômicas para sobreviver.

Diante de tal situação moralmente indefensável, em que há pobreza e desconsideração das construções culturais e políticas, faz-se necessário pensar o conflito pela lógica das teorias da justiça analisadas nesse artigo. Antes de aplicar e revisitar tais conceitos, cabe destacar as demandas do grupo, sintetizadas pelo antropólogo Sandro Silva:

1. Titular os territórios quilombolas; 2. Criar o fórum da juventude quilombola no estado; 3. Aplicação dos recursos ligados ao Fundo do Trabalhador nas comunidades quilombolas; 4. Gerar trabalho e renda baseado nas potencialidades das comunidades quilombolas; 5 . Construir e fomentar redes nacionais e internacionais de organizações de jovens; 6 . Criar um programa de desenvolvimento social e econômico local para a juventude nas comunidades quilombolas; 7. Criar um programa conjunto e dialogado entre jovens e políticas municipais e estaduais para desenvolvimento humano; 8 . Desenvolver ações de garantia de desenvolvimento baseada nas diferenças de gênero e geração; 9. Desenvolver ações de promoção da educação formal e saúde dos jovens quilombolas e 10. Criar a escola agrícola quilombola. (SILVA, 2013a, p. 27)

Observando as reivindicações acima, existem tanto demandas acerca da permanência da comunidade no lugar onde vive e da 
preservação da história de seus antepassados quanto reivindicações que só podem ser atendidas através de políticas socioeconômicas.

\subsection{O caso do quilombo de Linharinho: uma análise a partir do ponto de vista cosmopolita de Thomas Pogge}

Thomas Pogge se compromete com a ideia de que a ordem institucional internacional atual está diretamente ligada às graves violações dos direitos humanos, desfavorecendo uma parcela dos indivíduos do mundo.

No caso do quilombo de Linharinho, um grupo constituído por laços culturais e problemas materiais, tais direitos estão sendo violados. De acordo com Pogge, não importa a nacionalidade, a tradição e a religião do indivíduo, visto que todos serão tratados como iguais, independentemente de suas identificações e filiações. Em outras palavras, todos os seres humanos são unidades mínimas da moralidade. Justifica-se, assim, o estudo da proposta de Pogge para dar conta de algumas demandas feitas pelos quilombolas de Linharinho.

Para Pogge, os negros, as mulheres e os muitos jovens são os mais afetados pela pobreza, ou seja, não acessam os direitos socioeconômicos com facilidade. Tais danos sociais cometidos pela ordem global são previsíveis e, portanto, poderiam ser evitados sem um alto custo moral. A pobreza extrema contemporânea foi gerada, segundo o autor, por três fatores mundialmente compartilhados: a existência de uma ordem econômica global que beneficia os países ricos e agrava as desigualdades sociais nos países pobres; a exclusão não compensada do uso de uma base comum de recursos naturais e, por último, os efeitos de uma história compartilhada e violenta. De acordo com esse raciocínio, a justiça estaria relacionada ao dever negativo de não apoiar as instituições sociais que ajudam a manter a lógica da dominação e dos benefícios econômicos voltados para uma minoria rica.

Pogge argumenta que a pobreza global pode ser substancialmente reduzida através de reformas institucionais modestas que modifiquem, 
por exemplo, as regras que regulamentam o comércio internacional, os empréstimos, os investimentos e o uso de recursos em um âmbito universal. Essas medidas podem ser representadas pelo fim das regras protecionistas - como as realizadas pelos países ricos contra a importação dos bens e serviços advindos dos países pobres - e pelo término dos empréstimos de fundos internacionais que prejudicam e vinculam a economia dos países pobres.

Quando os países mais ricos aceitarem essas reformas institucionais, seriam gerados custos de oportunidade e de compensação que incidiriam em todas as transações comerciais. Esses custos objetivam incentivar, supervisionar e condicionar os habitantes do mundo a serem mais justos ao redistribuir os recursos para os indivíduos que se encontram em uma situação de desvantagem. Percebe-se, assim, que Pogge propõe reformas para o cenário econômico, não por meio da caridade, mas a partir de instrumentos que compensem os danos gerados pelos acordos institucionais injustos que causam o desrespeito aos direitos humanos dos pobres no mundo. Tais reformas, segundo o autor, são modestas, pois não sacrificariam aqueles que se encontram em uma situação vantajosa.

A teoria da justiça global de Pogge ampara-se no aporte normativo dos direitos humanos e em três pressupostos: o indivíduo, a universalidade e a generalidade. $O$ primeiro busca resguardar o ser humano como unidade mínima da moral; o segundo, garantir que cada unidade moral será considerada igualmente; e, finalmente, o status especial de cada indivíduo tem força global. Pogge sustenta uma concepção de justiça que respeite o cumprimento dos direitos humanos por meio de um ordenamento institucional justo. A existência da pobreza no mundo é moralmente indefensável e a solução não está concentrada na responsabilidade de um grupo, mas de todos que compartilham as mesmas instituições sociais injustas.

Expostos os arcabouços teóricos, a possível saída encontrada por Pogge para resolver os problemas da comunidade quilombola de Linharinho não decorreria dos direitos culturais em prol do grupo, mas dos 
direitos sociais voltados para solucionar as questões socioeconômicas. Pogge, portanto, alertaria que os membros da comunidade sofrem de privações materiais, falta de oportunidade igualitária e de discriminação social. Para enfrentar tais problemas, o autor, potencialmente, proporia políticas igualitárias e universais, como, por exemplo, a garantia de que os quilombolas tenham acesso aos programas sociais, aos direitos de alimentação, moradia, educação, emprego e saúde, e, por fim, medidas que evitassem a discriminação racial.

Não há necessidade de direitos diferenciados em função da comunidade, isto é, por demandas culturais. O fato de um grupo compartilhar a mesma ascendência, a mesma tradição e possuir limites específicos - em outras palavras, ser ou não étnico - é um aspecto secundário para a avaliação moral de Pogge. O autor não defende que um grupo étnico possa ser favorecido na distribuição dos direitos, já que todos os grupos, ainda que existam particularidades entre eles, devem ser considerados de forma igualitária e imparcial, pelo mesmo conjunto de direitos existentes.

Articulando as demandas expostas pela comunidade quilombola de Linharinho e a teoria de Pogge, acredita-se que o autor daria conta dos seguintes pontos: 1) geração de trabalho e renda; 2) construção e fomento das redes nacionais e internacionais sobre a organização dos jovens; 3) criação de um programa de desenvolvimento social e econômico local para a juventude quilombola; 4) concepção do programa conjunto e dialogado entre jovens e políticas municipais e estaduais para desenvolvimento humano; e 5) desenvolvimento de ações de promoção da educação formal e saúde dos jovens quilombolas.

Esses pontos foram definidos e associados a Pogge, pois possuem uma relação intrínseca com os direitos sociais. A proposta de Pogge, portanto, não seria capaz de dar conta das cinco reivindicações apresentadas pelo grupo, que, circunscritas aos direitos culturais e às singularidades identitárias, requerem um olhar atento e menos ampliado. Ao observar que algumas questões não foram vislumbradas por Pogge, faz-se necessário, nesse momento, analisar a proposta de Kymlicka. 
3.2 As questões culturais dos quilombolas de Linharinho e a proposta multicultural de Will Kymlicka

Na teoria de justiça de Kymlicka, há uma tentativa de fortalecimento cultural das minorias nacionais e étnico-culturais. As identidades étnicas e as suas respectivas singularidades são traços constantes que emergem nas sociedades contemporâneas e podem ser vistas como uma importante fonte de cultura, status social, construção de significados e ações políticas. Para resguardar essa pluralidade, Kymlicka propõe políticas institucionais que protejam e promovam as culturas minoritárias. Enfatiza, assim, medidas de justiça para o agrupamento social que possui uma cultura minoritária que não está sendo preservada, ainda que não ignore outros aspectos atrelados à justiça, pois "a injustiça que recai sobre os grupos étnicos se manifesta sob diversas dimensões raça, classe social e, notadamente, cultura" (BANTING; KYMLICKA, 2005, p. 122).

O caso concreto dos quilombolas de Linharinho descortinou um grupo de negros que possui tradições, religiões e práticas simbólicas que merecem ser resguardadas. Ainda que Kymlicka não trate diretamente do caso dos afrodescendentes que possuem formas de vidas singulares e uma cultura específica, não há dúvida de que eles seriam uma fonte de interesse moral para o autor, porque a discriminação étnico-racial não envolve apenas um problema social, mas também cultural.

Inicialmente, como visto, Kymlicka argumentava que os direitos humanos seriam insuficientes para garantir a justiça multicultural; daí a previsão de uma espécie de suplemento dos direitos humanos, traduzido pelos direitos diferenciados em prol do grupo, sobretudo devido a existência de poucos dispositivos para resguardar as minorias étnicas (KYMLICKA, 2011). Em seus estudos mais recentes, no entanto, Kymlicka defende que nos últimos vinte anos o multiculturalismo ganhou mais espaço no cenário mundial, o que pode ser demonstrado tanto pelos discursos políticos, como pelos dispositivos normativos. Atualmente, o autor não propõe mais uma suplementação, nem propriamente reformas institucionais globais, como Pogge, mas a construção de parâmetros 
institucionais para a observação e a aplicação dos direitos culturais (ARAUJO, 2006). Em seguida, demostra ser necessário estabelecer pontos de partida comuns para a aplicação do multiculturalismo. São eles: 1) o repúdio pela ideia moderna de que o Estado diz respeito a um único grupo nacional; 2) a não aceitação da política nacional que exclui os membros de uma minoria ou de um grupo não dominante; 3) o reconhecimento da injustiça histórica cometida contra as minorias e os grupos não dominantes (KYMLICKA, 2007a, p. 65-66).

De qualquer forma e apesar dos avanços do multiculturalismo, a compreensão desses pontos de partida comuns ainda é muito precária, bastando perceber a vagueza da linguagem utilizada nos dispositivos normativos em prol das minorias culturais, o que gera a ineficiência e a dificuldade de acessar os direitos. Esse é o caso do decreto brasileiro $\mathrm{n}^{\circ}$ 4887/03, que apesar de resguardar o direito de propriedade aos povos "remanescentes de quilombolas", garantiu apenas o título da terra a 17 comunidades, de um total de 2.007 certificadas pela Fundação Cultural Palmares ${ }^{12}$.

Além disso, de acordo com Kymlicka, muitos políticos e teóricos assumem uma postura contrária ao multiculturalismo, alegando que ele fere os direitos humanos. Ao contestar, o autor destaca que os direitos das minorias culturais fazem parte dos direitos humanos, com eles coexistindo e operando dentro dos seus limites. Por esta razão, sustenta que o multiculturalismo não endossa os arranjos institucionais que potencialmente prejudicam os próprios membros do grupo, mas, de fato, contribui para reforçar a justiça entre os grupos no Estado liberal. Há, portanto, um compromisso com os princípios da liberdade individual e ${ }^{13}$ da igualdade.

\footnotetext{
12 Para maiores informações, acessar os relatórios da Fundação Cultural Palmares, no seguinte endereço: <http://www.palmares.gov.br/quilombola/> (acessado em 04/03/2014).

13 O termo "remanescente de quilombolas" utilizado no decreto não pode ser interpretado de forma estrita, pois corre-se o risco de deixar muitas comunidades campesinas negras sem o reconhecimento.
} 
Dadas essas considerações, é razoável supor que para Kymlicka a origem da desvantagem dos quilombolas de Linharinho é de natureza cultural, e, por isso, a solução deveria se concentrar no reconhecimento das identidades locais. Torna-se necessária a observação de mecanismos normativos em prol do grupo, para fortalecer, notadamente, as tradições, as religiões e as práticas culturais, com relevância para os seguintes mecanismos: os direitos de autogoverno; os direitos especiais de representação e os direitos poli-étnicos (KYMLICKA, 1995, p. 37-38).

Por meio das pautas de reivindicações dos quilombolas de Linharinho, Kymlicka certamente daria prioridade aos seguintes pontos: 1) regularização formal dos territórios quilombolas; 2) criação do fórum da juventude quilombola no Estado; 3) desenvolvimento de ações baseadas nas diferenças de gênero e geração; 4) promoção da educação formal e saúde dos jovens quilombolas; e 5) construção da escola agrícola quilombola. Tais tópicos foram associados a Kymlicka, tendo em vista o conteúdo cultural dos interesses morais da teoria multicultural. Ressaltese que o autor reivindica direitos e formas institucionais de inclusão das minorias em um cenário sociopolítico, nacional e internacional. Nesse sentido, a fim de combater as discriminações étnicas e raciais sofridas pelos quilombolas de Linharinho, Kymlicka possivelmente legitimaria as políticas de identidade ao resguardar os bens criados e herdados pelo grupo, ao garantir o acesso formal à terra e aos espaços de discussão, além de ações baseadas nas construções locais, como a escola agrícola. Portanto, a ferramenta teórica do multiculturalismo liberal seria usada para resguardar e dar voz às demandas locais.

\section{Conclusão}

Aconclusão não poderia ser outra senão a de perceber que Thomas Pogge enfrentaria o desafio do caso dos quilombolas de Linharinho a partir do garantia dos direitos sociais, assegurando, assim, o acesso aos bens básicos, como alimentação, educação, moradia, emprego e saúde. A viabilidade de tal modelo ocorreria por meio do aporte normativo dos direitos humanos e, posteriormente, através de uma reforma institucional 
que redistribuísse os recursos materiais. Esse modelo de justiça encontra amparo em âmbito internacional, visto que todos os indivíduos abastados do mundo são responsáveis pelos danos causados àqueles que se encontram em uma situação de desvantagem. Estamos diante, portanto, do dever negativo de não sustentar as instituições que causam a pobreza aos membros do quilombo de Linharinho, o que resulta no compromisso mundial de solucionar as demandas sociais do grupo.

Kymlicka, por seu turno, admitiria que os quilombolas de Linharinho sofrem injustiças em função da ausência de reconhecimento cultural. Desse modo, seriam evocados, inicialmente, os mecanismos normativos que protegem a relevância cultural das práticas locais, como os direitos diferenciados - destinados aos indivíduos pertencentes ao grupo - e, em seguida, a elaboração dos meios para efetivá-los. A justiça multicultural seria concretizada ao serem resguardadas as práticas locais do quilombo de Linharinho.

Sustentou-se, ao longo desse texto, a hipótese de que as duas teorias observadas de forma isolada não conseguiriam dar conta dos problemas da justiça de uma sociedade contemporânea complexa que demanda a redistribuição de recursos, o reconhecimento cultural e a representação política. Após a análise do caso concreto dos quilombolas de Linharinho, tornou-se ainda mais claro que apenas uma teoria da justiça não seria suficiente para corrigir as desigualdades encontradas. A partir do mapeamento das reivindicações do grupo, observa-se o entrelaçamento simultâneo das dimensões econômica, cultural e política. Para solucionar de forma satisfatória as questões complexas que foram relatadas e dizem respeito ao quilombo de Linharinho, seria enfim insuficiente a aplicação isolada tanto da proposta de Pogge, quanto do modelo de Kymlicka.

Mesmo não sendo uma tarefa simples, é possível observar uma certa convergência entre as duas teorias de justiça. Por ora, destaca-se, brevemente, que as duas utilizam os dispositivos normativos expostos na Declaração Universal dos Diretos Humanos, sustentam os princípios do liberalismo igualitário e propõem formas institucionais como garantia 
da justiça. Em contrapartida, há divergências, como, por exemplo, a crítica de Pogge às distinções conceituais entre os grupos étnicos e os não étnicos, de modo que estas referências culturais não são relevantes para concretização de direitos. Kymlicka, por sua vez, identifica a importância dos direitos sociais, porque assume que a política cultural é atravessada por relações socioeconômicas; dificilmente, no entanto, abriria mão dos direitos diferenciados em favor destas demandas de natureza socioeconômicas.

Por fim, as duas propostas igualmente formulam modelos de justiça social. Tanto para Pogge como para Kymlicka, a justiça ou seu oposto são questões de planejamento institucional. Os esforços teóricos desses autores estão atrelados a esta determinação; por isso, nenhum deles comprometeu-se com algum apelo ético, voltado para a avaliação pessoal dos envolvidos, mas, ao contrário, sustentaram uma justiça alicerçada na premissa de que os arranjos institucionais são os responsáveis pela disposição dos direitos e das oportunidades. Há, sem dúvida, muitas outras questões que necessitariam de respostas, endereçadas, notadamente, às responsabilidades, reformas e obrigações relativas aos modelos de justiça, pois, afinal, sabemos que os mecanismos de ordem institucional nem sempre são suficientes para, de fato, impedir a ocorrência de injustiças. Tais respostas, contudo, serão dadas em outra oportunidade.

\section{Referências}

ALBERTI, Verena. Ouvir contar: textos em história oral. Rio de Janeiro: Editora FGV, 2004.

ARAUJO, Marcelo de. Direitos individuais e direitos de minorias nacionais: uma crítica à política de "suplementação" dos direitos humanos em contextos multiculturais. Revista de Direito constitucional e internacional, São Paulo, v.55, p. 89-127. 2006

BANTING, Keith; KYMLICKA, WILL. Les politiques de multiculturalisme nuisent-elles à l'État-providence? Lien social et Politiques, Montreal, n. 53, p. 119-127, 2005. 
BARRY, Brian. Culture and equality: an egalitarian critique of multiculturalism. Cambrigde-Mass: Harvard University Press, 2001.

BRASIL. ADCT 68. Disponível em: <http://www.planalto.gov.br/ccivil_03/ constituicao/constituicao.htm\#adct>. Acesso em: 24 mar. 14.

. Constituição (1988). Constituição da República Federativa do Brasil. Disponível em: <http://www.planalto.gov.br/ccivil_03/ constituicao/constituicao.htm>. Acesso em: 24 mar. 14.

Decreto Presidencial $n^{\circ}$ 4.887, de 20 de novembro de 2003. Disponível em: <http://www.planalto.gov.br/ccivil_03/decreto/2003/ d4887.htm>. Acesso em: 24 mar. 14.

BUZAN, Barry; HELD, David; MCGREW, Anthony. Realism vs Cosmopolitanism: a debate between Barry Buzan and David Held, conducted by Anthony McGrew. Review of International Studies, Cambridge, v. 24, n.3, p. 387-398, 1998.

CEPALUNI, Gabriel e GUIMARÃES, Feliciano. "Discípulos de Rawls em busca de uma concepção cosmopolita de justiça distributiva internacional". Revista Sociologia Política, Curitiba, v. 18, n. 37, p. 5973, 2010.

FERREIRA, Marieta de M.; AMADO, Janaína (Orgs.). Usos e abusos da história oral. Rio de Janeiro: Fundação Getulio Vargas, 1996.

FERREIRA, Simone. “'Donos do lugar”: a geo-grafia negra e camponesa do Sapê do Norte - ES" Revista Geografares, Vitória, n. 8, p. 1-19, 2010

FRASER, Nancy. Reenquadrando a Justiça em um mundo globalizado. Lua Nova, São Paulo, n. 77, p. 11-39, 2009.

FORST, Rainer. Contextos da justiça: filosofia política para além do liberalismo e comunitarismo. Tradução de Denilson Luís Werle. São Paulo: Boitempo, 2010.

FUNDAÇÃO CULTURAL PALMARES. Relatório de identificação das comunidades quilombolas dos Estados brasileiros. Disponível em: <http://www.palmares.gov.br/quilombola/>. Acessado em: 04 mar. 2014. 
HELD, David. The transformation of political community: rethinking democracy in the context of globalization. In: SHAPIRO, lan; HACKERCORDON, Casiano (Eds). Democracy's Edges. Cambridge: Cambridge University Press, 1999. p. 84-11.

JAGGAR, Alison (Ed.). Thomas Pogge and his critics. Polity: Malden, 2010.

KYMLICKA, Will. Filosofia política contemporânea. São Paulo: Martins Fontes, 2006

. Do we need a liberal theory of minority rights? Reply to Carens, Young, Parekh and Forst. Constellations, v. 4, n. 1, p. 72-87, 1997.

Multiculturalism: success, failure and the future. Washington: Migration Policy Institute, 2012.

- Liberalism, community, and culture. Oxford: Clarendon Press, 1989.

Multicultural Citizenship: A liberal theory of minority rights. Oxford: Clarendon Press, 1995.

- Multicultural odysseys: navigating the new international politics of diversity. Oxford: Clarendon Press, 2007.

. Direitos humanos e justiça etnocultural. Meritum,. Belo Horizonte, v. 6, n. 2, p. 13-55, 2011.

. États Du multiculturalisme. Raison publique, Paris, n. 9, p. 31-45, 2008.

. Community and Multiculturalism. In: GOODIN, P. Pettit. A Companion to contemporary philosophy. Oxford: Blackwell Publishing, 2007b. v. 1, p. 463-477.

Politics in the vernacular: nationalism, multiculturalism, and citizenship. Oxford: Clarendon Press, 2001. 
LIMA, Antonio Carlos de Souza; BARROSO-HOFFMANN, Maria et al (Orgs.). Além da tutela bases para uma nova política indigenista III. Rio de Janeiro: LACED, 2002.

MATTOS, Hebe . Remanescentes das comunidades dos quilombolas: memória do cativeiro e políticas de reparação no Brasil. Revista USP, São Paulo, n. 68, p. 104-111, 2006.

MOURA, Julia . Compreendendo a utopia realizável: uma defesa do ideal de justiça distributiva da teoria de John Rawls. 2013. 204 f. Tese (Doutorado em Filosofia) - Programa de Pós-Graduação em Filosofia, Instituto de Filosofia e Ciências Humanas, Universidade do Estado do Rio de Janeiro, Rio de Janeiro, 2013.

PATTEN, Alan; KYMLICKA, Will. Language rights and political theory. Oxford: University Press, 2003.

POGGE, Thomas. World poverty and human rights. Malden: Polity Press, 2008a.

- Cosmopolitanism. In: GOODIN, P. Pettit. A Companion to contemporary philosophy. Oxford: Blackwell Publishing, 2007. p. 312331 , v. 1.

. Para erradicar a pobreza sistêmica: em defesa de um dividendo dos recursos globais. Sur - Revista internacional de direitos humanos, São Paulo, v. 6, p. 142-161, 2007.

- ¿Qué es la justicia global? Revista de economía institucional, Bogotá, v. 10, n. 19, p.99-114, 2008.

- La Incoherencia entre las Teorías de la Justicia de Rawls. Revista Internacional de Filosofía Política, Cidade do México, n. 23, p. 28-48, 2004.

Group rights and ethnicity. In: SAPHIRO, Ian; KYMLICKA, Will. Ethnicity and group rights. New York: New York University Press, 1997. p. 16-35.

. Accommodation rights for hispanics in the U.S. In: PATTEN, Alan; KYMLICKA, Will. Language rights and political theory. Oxford: University Press, 2003. p. 3-21. 
- Reconhecidos e violados pela lei internacional: os direitos humanos dos pobres no mundo". Ethic@, Florianópolis, v. 5, n. 1. p. 33-65, 2006.

. Hacer justicia a la humanidad. Tradução de David Álvarez García. México: Fondo de Cultura Económica, 2013.

RAÇA. Dirigido e produzido por Joel Zito Araújo e Megan Mylan. Brasil, Estados Unidos: Espaços filmes, 2012. Vídeo/cor (104 min.): DVD, son., color.

RAWLS, John 0 direito dos povos. Tradução de Luís Carlos Borges. São Paulo: Martins Fontes, 2001.

. Uma teoria da justiça. Tradução de Jussara Simões. 3. ed. São Paulo: Martins Fontes, 2008.

. Justice as fairness: a restatement. Harvard: Harvard Univ. Press, 2001.

- Justiça como Equidade: uma concepção política, não metafísica”. Lua Nova, São Paulo, n. 25, p. 25-59, 1992.

RELATÓRIO DE DESENVOLVIMENTO HUMANO. A ascensão do Sul: progresso humano num mundo diversificado. Lisboa: Instituto Português de Apoio ao Desenvolvimento, 2013.

RODAS, Francisco Cortés. Una crítica a las teorias de justicia global: al realismo, a Rawls, Habermas y Pogge. Ideas y valores, Bogotá, n. 142. p. 93-110, 2010.

SILVA, Sandro Do Fundo daqui: Iuta política e identidade quilombola no Espirito Santo. 2012. 342 f. Tese (Doutorado em Antropologia) Programa de Pós-Graduação em Antropologia, Instituto de Filosofia e Ciências Humanas, Universidade Federal Fluminense, Niterói, 2012.

. Cartografia dos quilombolas e do carvão no Sapê do Norte. Vitória: EDUFES, 2013.

VITA, Álvaro Liberalismo Igualitário e multiculturalismo (sobre Brian Barry, Culture and Equality)". Lua Nova, São Paulo, v.55-56, p. 05-27, 2002. 
YOUNG, Iris "A multicultural continuum: a critique of Will Kymlicka's ethnic-nation dichotomy". Constellations, New York, v. 4, n. 1, p. 48-53, 1997.

Recebido em: 26/03/2015

Aprovado em: 31/03/2015 